\title{
Highlights of genitourinary cancer research presented at ASCO 2017
}

\section{Naveen S. Basappa, MD, FRCPC'; Anil Kapoor, MD, FRCSC ${ }^{2}$}

'Cross Cancer Institute \& University of Alberta, Edmonton, AB, Canada; ${ }^{2}$ CUAJ Associate Editor \& McMaster University, Hamilton, ON; Canada

Cite as: Can Urol Assoc J 2017; 11 (8Supp15):S297. http://dx.doi.org/10.5489/cuaj.4839

$\Delta$ t the 2017 annual meeting of the American Society of Clinical Oncology (ASCO), there was a wealth of new information presented in the field of genitourinary (GU) cancers. The following pages provide a summary of findings of several key studies investigating selected themes in kidney, bladder, and prostate cancers. For kidney, the focus of the summary is on new research with tyrosine kin- ase inhibitors (TKIs; e.g., pazopanib, sunitinib). In bladder cancer, the summary focuses on immuno-oncology, with highlights of new trials evaluating checkpoint inhibitors in this tumour type. Finally, in prostate cancer, the summary includes synopses of new evidence with the oral hormonal agents abiraterone acetate and enzalutamide.

Acknowledgement: The authors would like to thank STA Communications for editorial assistance with this report. 